\title{
Safety Traceability System of Characteristic Food Based on RFID and EPC Internet of Things
}

\author{
https://doi.org/10.3991/ijoe.v15i05.10128 \\ Chenglong Zhang $\left({ }^{\square}\right)$ \\ Guizhou University, Guiyang, China \\ lishaobo@gzu.edu.cn \\ Shaobo Li \\ Guizhou University, Guiyang, China \\ Jinglei Qu \\ Henan Institute of Technology, Xinxiang, China
}

\begin{abstract}
In order to realize the safe traceability of the whole life cycle of the "Old Godmother Flavor Food", the RFID (Radio Frequency Identification Devices) technology is applied to the data acquisition of raw material purchasing, production processing, warehousing management, logistics and transportation. A kind of special food safety traceability network model was put forward based on RFID technology, and the RFID label EPC encoding rules are designed on "Old Godmother Flavor Food"; according to the demand analysis of characteristic food safety traceability system, the system design and implementation are carried out based on $\mathrm{B} / \mathrm{S}$ and $\mathrm{C} / \mathrm{S}$ architecture.
\end{abstract}

Keywords-Food Safety, Traceability system, Internet of Things, Product electronic code, Radio Frequency Identification Devices

\section{Introduction}

In recent years, many researchers at home and abroad have been devoted to the study of product safety traceability, and have proposed many effective methods and models for traceability [1-3]. However, due to the impact of technological level, practice environment and related factors, it has not yet realized the safe traceability of food life cycle from raw material procurement, production processing, warehousing management, logistics and transportation [4-6].

RFID technology compared with other automatic identification technology has its own unique properties and advantages, it is in the material tracking, vehicle and cargo identification requirements such as non-contact data acquisition, information exchange and storage applications has broad prospects for development [7-8]. Therefore, this article uses the RFID technology to carry on the life cycle data collection of the characteristic food, and designs the RFID label EPC coding rule for "Old Godmother Flavor Food" [9-10]. It can effectively guarantee the integrity and accuracy of 
the collected information and according to the model of characteristic food safety traceability network, the design and implementation of the traceability system of characteristic food safety based on $\mathrm{B} / \mathrm{S}$ and $\mathrm{C} / \mathrm{S}$ architecture has been completed.

\section{New Models of Intelligent Manufacturing in Electronic Component Industry}

Characteristic food safety traceability system based EPC-RFID technology is the service platform for enterprise, sales point and consumer with information sharing as the ultimate goal. Through the application of RFID technology, we can trace the information of all aspects of the whole life cycle of the "Old Godmother Flavor Food", and provide strong data support for the characteristic food safety traceability. The overall structure of the traceability system is constructed (As shown in Fig. 1).

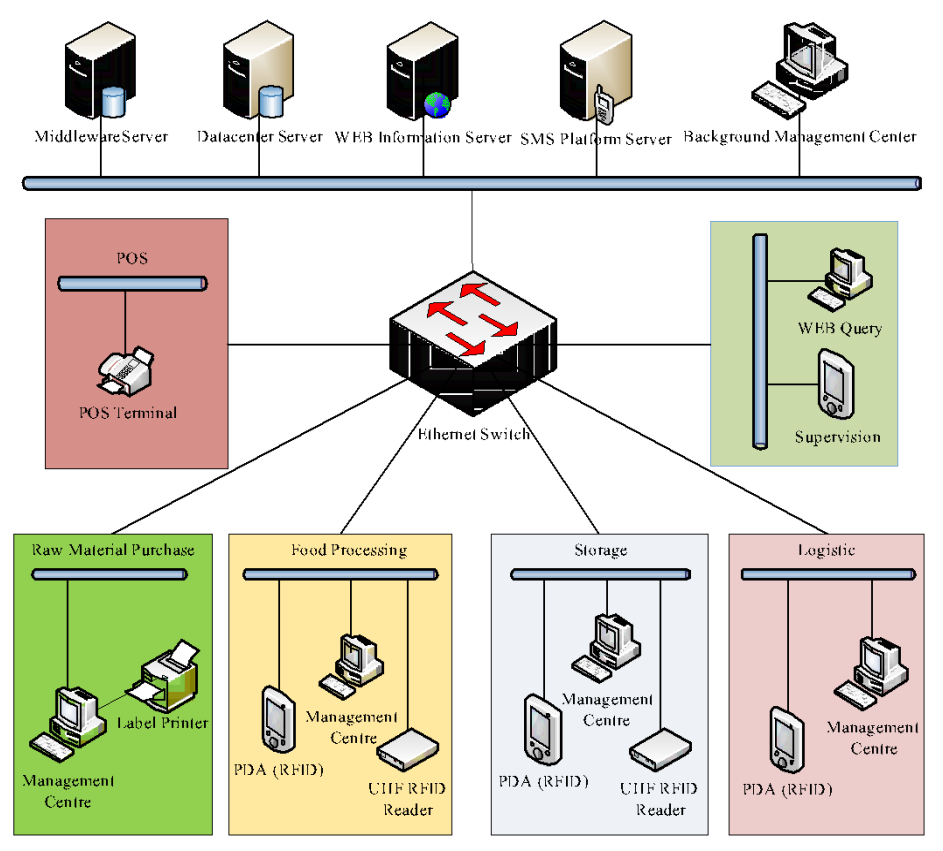

Fig. 1. The intelligent design and product data management architecture

RFID technology is used to collect the raw materials purchasing, production, processing, storage management, logistics and transportation data of the "Old Godmother Flavor Food", and store the data of each link automatically in the traceability system database, At the same time, when the characteristic food production is completed, RFID labels with related information to the system database are used to identify the same batch of food, the EPC encoding code in the RFID tag was transferred into label on the product of small packaging for consumer inquiries using. Consumers can ob- 
tain product information through the server by inputting the product traceability code at the terminal interface of the traceability system.

\section{EPC Encoding Design of Characteristics Food}

\subsection{EPC encoding design plan}

EPC encoding is an important component of RFID tags. It encodes the relevant information of entities and entities, and establishes a global information exchange language through standardized and unified coding.

For the coding choice of "Old Godmother Flavor Food" , a universal identification type defined by the EPC encoding data standard is selected. The generic identifier is GID-96 (General, Identifier-96, 96 bit universal identifier) [11-12], this universal identifier consists of 3 fields, include 32 bit EPC domain manager code, 32 bit object classification code, and 32 bit serial number. It does not rely on any known, existing specification, or identification scheme.

Coding rules and coding structures based on coding systems, combining the production characteristics of condiment enterprises and the investigation of various products in the market, the design and allocation of the EPC coding region are presented to make it unique, permanent, simple and extensible. The code assignments are shown in Fig. 2. Among them, the code section capacity is $\mathrm{n}(\mathrm{n}$ is the number of digits, and the whole 0 sequence is the initialization sequence).

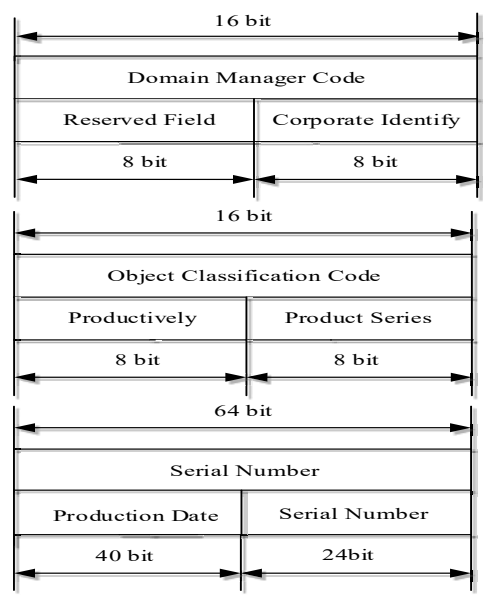

Fig. 2. The EPC code assignments

General identifier GID-96 contains domain manager code, object classification code, and serial number three fields, composed of a binary number, to identify objects related information for storage, realize the unique identification of individual products. The coding procedure is as follows: 


\section{It's defined as follows :}

- Define $\mathrm{M}$ for domain manager code;

- Define O for object classification code;

- Define S for serial number code;

The flow chart of specific encoding program is shown in Fig. 3:

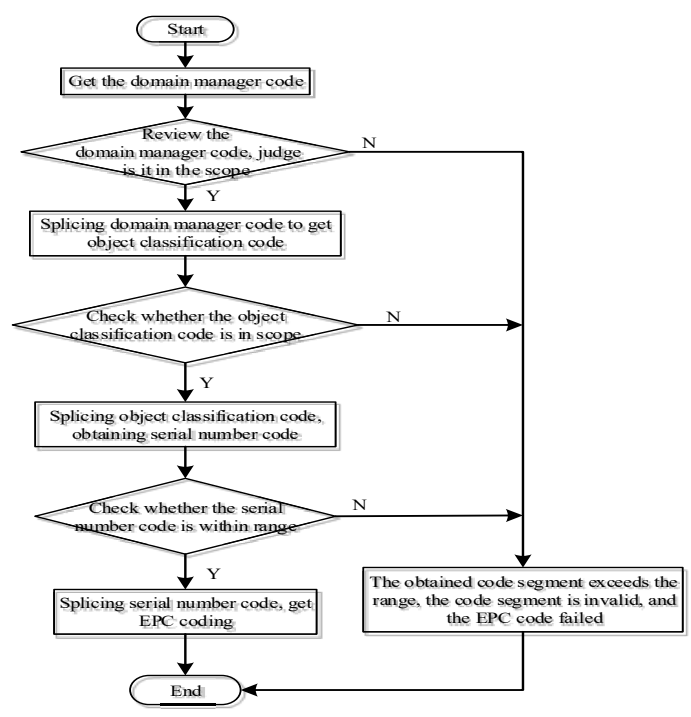

Fig. 3. The flow chart of specific encoding program

\subsection{Encoding example}

According to the above coding method, in the domain name manager code, 8 of the field is reserved, 0 initial, and the company logo - Guiyang Nanming Old Godmother Flavor Food limited liability company marked as 0000, 0001; in the object classification code, the selling place China is identified as 0000, 0001 and the product series refined beef, fermented bean oil and chilli is marked as 0000,0001 ; in the serial number code, the product date was marked as $0010,1110,1111,1100,1101,0010,1010$, $1110,0100,1110$ for 12:30 October 16, 2018, marking one of the millions of products on that day as $0000,0000,0000,0000,0000,0001$. Get a single product encoding as shown in Table 1.

Table 1. A single product code

\begin{tabular}{|c|c|c|c|}
\hline 96 & M & $\mathbf{O}$ & $\mathbf{S}$ \\
\hline bit & 16 & 16 & 64 \\
\hline Binary value & $0000,0000,0000,0001$ & $0000,0001,0000,0001$ & $\begin{array}{c}0010,1110,1111,1100,1101,0010, \\
1010,1110,0100,1110,0000,0000, \\
0000,0000,0000,0001\end{array}$ \\
\hline
\end{tabular}




\section{System Design and Implementation}

The purpose of characteristic food safety traceability system is to promote the enterprise's production information transformation, improve the production efficiency, and ensure the market competitiveness of enterprises. According to the enterprise demand analysis, the whole system design and the system software architecture, combined with the actual production situation of the enterprise, the structured programming method is adopted to divide the main functions of the system, Fig. 4 is the functional module structure of food safety traceability system, mainly including the procurement subsystem of raw materials, production and processing subsystem, storage management subsystem, logistics transportation terminal sales subsystem, WEB subsystem, traceability query subsystem, supervision query subsystem, the backstage management center of 8 parts.

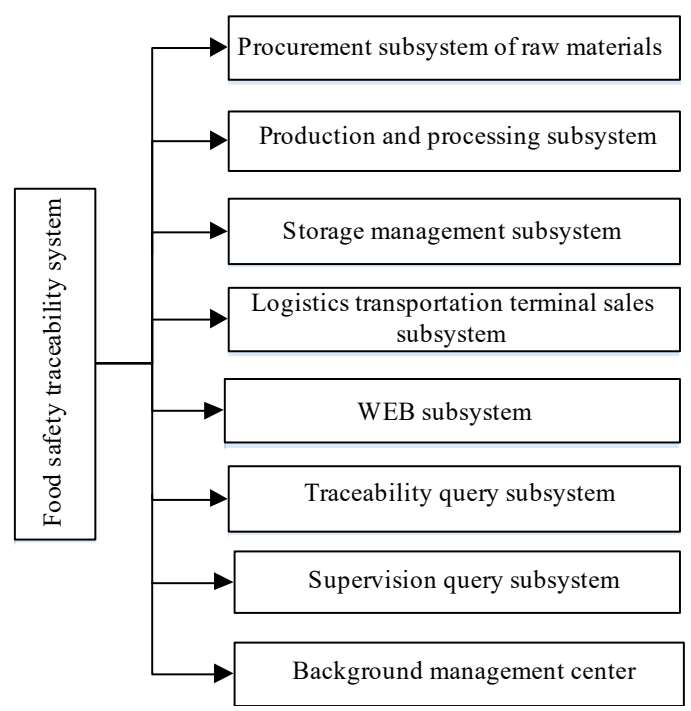

Fig. 4. The functional module structure of food safety traceability system

The characteristic food safety traceability system designed in this paper uses Microsoft SQL Server 2008 as the database server of the platform, and under the Microsoft Visual Studio 2015 development platform, the application C\# programming language development and implementation. The system has completed the construction of the physical environment in the laboratory, the specific environment as shown in Fig. 5. When the system test is completed, practical application will be made in the project cooperation unit, Guiyang, Naming Old Godmother Flavor Food limited liability company, which help reduce costs and risks and improve product quality and safety credibility, to achieve organic unity of enterprise management and safety in production, at the same time can clearly define the responsibility for food quality and safety issues, and protect the legitimate rights and interests of consumers and enterprises. 


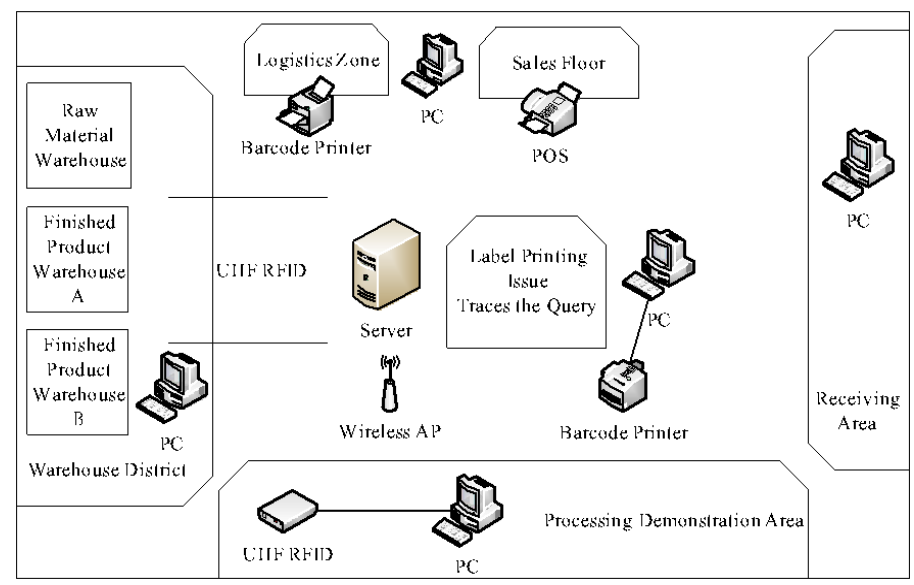

Fig. 5. The construction of the physical environment

The production and processing subsystem page of characteristic food safety traceability system as shown in Fig. 6, which includes process management, production work order management, input information query, test information management, product packaging management, quality reviews and other parts.

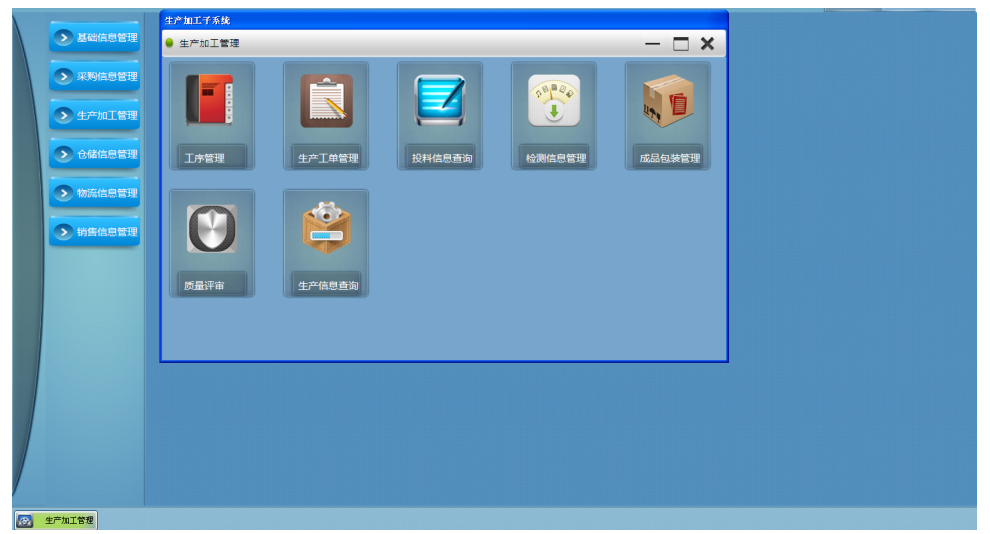

Fig. 6. The characteristic food safety traceability system home page

\section{Conclusion}

The design and development of the characteristic food safety traceability system based on EPC-RFID Technology in this article, the coding design of characteristic food is carried out by using EPC coding standard, the whole life cycle of characteristic food is marked with RFID label, and the whole process of all aspects of characteristic food is traced back. The realization and popularization of this research can pro- 
vide reference for the establishment of meat, vegetable and other food traceability system.

\section{Acknowledgement}

This work was supported by national Natural Science Foundation of China (51475097 and 61540066), Science and Technology Foundation of Guizhou Province (JZ[2014]2001), and National Key Technology Support Program of China (2012BAH62F00).

\section{$7 \quad$ References}

[1] Pérez M M, González G V, Dafonte C. (2016). Safety and Traceability in Patient Healthcare through the Integration of RFID Technology for Intravenous Mixtures in the Prescription-Validation-Elaboration-Dispensation-Administration Circuit to Day Hospital Patients. Sensors, 16:1188-1210. https://doi.org/10.3390/s16081188

[2] Dai Hongyan, Ge Ling, Zhou Weihua . (2015). A design method for supply chain traceability systems with aligned interests. International Journal of Production Economics, 170:14-24. https://doi.org/10.1016/j.ijpe.2015.08.010

[3] Li Shaobo, Qu Jinglei, Zhang Chenglong. (2017). Real-time resource positioning system based on wireless sensor network in manufacturing workshop. International Journal of Online Engineering, 13(6): 96-104 https://doi.org/10.3991/ijoe.v13i06.6933

[4] Xu Xiaohua. (2017). Quality and Safety Traceability System of Aquatic Products Based on Internet of Things. International Journal of Online Engineering, 13(9): 96-104 https://doi.org/10.3991/ijoe.v13i09.7590

[5] Pan Juan, Zhu xiaodong, Yang Li, et al. (2011). Research and Implementation of Safe Production and Quality Traceability System for Fruit// Computer and Computing Technologies in Agriculture V. Springer Berlin Heidelberg, 133-139

[6] Mimmo T, Camin F, Bontempo L, et al. (2015). Traceability of different apple varieties by multivariate analysis of isotope ratio mass spectrometry data. Rapid Communications in Mass Spectrometry, 29(21):1984-1990. https://doi.org/10.1002/rcm.7306

[7] Chen Ning, Yue Qingqing. (2017). Campus Intelligent Safety Supervision System Based on RFID. International Journal of Online Engineering, 13(11): 96-104 https://doi.org/10.3991/ijoe.v13i11.7663

[8] Fan Tijun, Tao Feng, Deng Sheng, et al. (2015). Impact of RFID technology on supply chain decisions with inventory inaccuracies. International Journal of Production Economics, 159:117-125. https://doi.org/10.1016/j.ijpe.2014.10.004

[9] Jing Changfeng, Du Mingyi, Shang Likun. (2015). A Low-cost RFID/GPS Location Sensing Algorithm for Urban Infrastructure. International Journal of Online Engineering, 11(4):4-7 http://dx.doi.org/10.3991/ijoe.v11i4.4319

[10] Yin Jun, Yi Jun, Man K L, et al. (2010). A system-on-chip EPC Gen-2 passive UHF RFID tag with embedded temperature sensor. IEEE Journal of Solid-State Circuits Solid-State Circuits, 45(11): 2404-2420

[11] Yoon E J. (2012). Improvement of the securing RFID systems conforming to EPC Class 1 Generation 2 standard. Expert Systems with Applications, 39(1):1589-1594. https://doi.org/10.1016/j.eswa.2011.07.053 
[12] Xu Min. (2012). Research on Tag Code Plan for Mine Internet of Things Based on EPC GID-96. Coal Science \& Technology, 40(5):70-73

\section{Authors}

Chenglong Zhang is now pursuing his master degree in college of big data and information engineering at Guizhou University, Guiyang, China, 550025. His research interests include manufacturing information system and internet things of technology, wireless sensor network (995010174@qq.com).

Shaobo Li is currently a professor of School of Mechanical Engineering at Guizhou Unversity, Guiyang, China, 550025. His research interests include computational intelligence, manufacturing information system and internet things of technology. $\mathrm{He}$ is a member of the IEEE, CMES and CCF (lishaobo@gzu.edu.cn).

Jinglei Qu is currently a lecturer of Department of Mechanical Engineering at Henan Institute of Technology, Xinxiang, China, 453000. His research interests include computational intelligence, manufacturing information system and data mining (jinglei0526@163.com).

Article submitted 2019-01-08. Resubmitted 2019-02-19. Final acceptance 2019-02-19. Final version published as submitted by the authors. 